\title{
Two-year Outcome of Quality of Life and Health Status for the Elderly with Chronic Limb- threatening Ischemia
}

This article was published in the following Dove Press journal: Clinical Interventions in Aging

\author{
Chloé ML Peters' \\ Paul Lodder ${ }^{2,3}$ \\ Jolanda de Vries (iD ${ }^{2,4}$ \\ Stijn L Steunenberg (iD) \\ Eelco J Veen' \\ Hans GW de Groot (iD) \\ Gwan H Ho' \\ Lijckle van der Laan ${ }^{1,5}$ \\ 'Department of Surgery, Amphia Hospital, \\ Breda, The Netherlands; ${ }^{2}$ Department of \\ Medical and Clinical Psychology, Tilburg \\ University, Tilburg, The Netherlands; \\ ${ }^{3}$ Department of Methodology and Statistics, \\ Tilburg University, Tilburg, The \\ Netherlands; ${ }^{4}$ Department of Medical \\ Psychology, Elisabeth-TweeSteden Hospital \\ Tilburg University, Tilburg, The \\ Netherlands; ${ }^{5}$ Department of \\ Cardiovascular Science, UZ Leuven - \\ University Hospitals, Leuven, Belgium
}

Correspondence: Lijckle van der Laan Amphia Hospital, Molengracht 21, Breda, CK 4818, the Netherlands

Tel +3I 765955000

Email Ivanderlaan@amphia.nl
Purpose: In elderly patients with chronic limb-threatening ischemia (CLTI), there is little scientific understanding of the long-term changes of quality of life (QoL) and health status (HS) after treatment. The primary goal of this study was to provide long-term QoL and HS results for elderly CLTI patients after therapy. Treatments consisted of endovascular revascularization, surgical revascularization, or conservative treatment. Furthermore, the aim of this study was to identify the distinctive trajectories of QoL and HS.

Patients and Methods: CLTI patients aged $\geq 70$ years were included in a prospective observational cohort study with a two-year follow-up. The WHOQOL-BREF was used to asses QoL. The 12-Item Short Form Health Survey was used to measure HS. The QoL and HS scores were compared to the scores in the general elderly Dutch population. Latent class trajectory analysis was used.

Results: A total of 195 patients were included in this study. After two years, in all treatment groups patients showed significantly higher physical QoL score compared to baseline and there was no significant difference with the corresponding values in the elderly Dutch population. In the latent class trajectory analysis, there were no overlapping risk factors for poorer QoL or HS. Conclusion: This study shows that QoL levels in surviving elderly CLTI patients in the long-term do not differ from the corresponding values for elderly in the general population. There were no disparities in sociodemographic, clinical and treatment characteristics associated with poorer QoL and HS. This study was carried out to encourage further analysis of the influence of biopsychosocial characteristics on QoL and HS in elderly CLTI patients.

Keywords: quality of life, health status, peripheral arterial disease, frail elderly, chronic limb-threatening ischemia

\section{Introduction}

The end stage of peripheral arterial disease is represented by chronic limb-threatening ischemia (CLTI). This disease is characterized by ischemic rest pain and/or tissue necrosis. ${ }^{1-3}$ CLTI diminishes quality of life (QoL) considerably and is associated with high mortality and morbidity rates. ${ }^{4-7}$ Revascularization (surgical or endovascular) is the cornerstone in the treatment of CLTI patients. ${ }^{1}$ However, scientific data is scarce to determine the best revascularization management in elderly (aged $\geq 70$ years) CLTI patients. ${ }^{6-8}$ Moreover, revascularization is not always an option in frail elderly patients. In these patients, conservative treatment is a possible approach. ${ }^{9-11}$ However, objective clinical outcome measures of conservative treatment are poor. 
Lately, primary end points of treatment for CLTI have changed from clinical outcome, such as bypass patency and survival, to patient-reported outcome measures, most prominently QoL and health status (HS). Some research has been carried out on the long-term changes of these patient-reported outcome measures. ${ }^{12,13}$ Still, there is little scientific understanding of the long-term changes of QoL and HS after the treatment of elderly CLTI patients. ${ }^{13,14}$

Poorer QoL and HS over time can be associated with patient characteristics. ${ }^{15}$ The course of a measured variable over time, such as QoL and HS, is called a trajectory. Latent class trajectory analysis is used to measure the relationship between distinctive trajectories and sociodemographic and clinical variables. In elderly CLTI patients, it is unclear which of these variables can influence the course of QoL and HS. Intermittent claudication (IC) is also a peripheral arterial disease and sometimes a precursor of CLTI. In IC patients, we know that poorer HS is associated with younger age, female sex, cardiac disease, worsening ankle-brachial index and not having a partner. ${ }^{17-20}$ To our knowledge, no studies have focused on the course of elderly CLTI patients' QoL or HS after treatment. In elderly CLTI patients, we expect high age, tissue loss (eg Rutherford 5/6) and comorbidities to result in poorer QoL and HS. Insight in variables, that can influence the QoL and HS trajectories of elderly CLTI patients, gives health-care providers the opportunity to monitor specific patients more carefully. As a result of insufficient information concerning these trajectories, health-care providers are restricted in making evidencebased decisions.

The primary goal of the present study was to provide long-term QoL and HS results for elderly CLTI patients after primary therapy: endovascular revascularization, surgical revascularization, or conservative treatment. The QoL and HS scores of this study's elderly sample were compared to the normal scores in the general elderly population. The second goal was to identify within the entire CLTI patient group distinctive trajectories of QoL and HS, followed by an assessment of the clinical and sociodemographic variables associated with each trajectory.

\section{Patients and Methods}

In this prospective observational cohort study, elderly CLTI patients were included between January 2012 and February 2016 in two hospitals. ${ }^{11}$ Inclusion criteria were diagnosis with CLTI and an age of 70 years or older. Because of the use of questionnaires, patients with a lack of Dutch language skills and cognitive impairment were excluded. Patients treated for, or with, a recent diagnosis of malignancy and patients undergoing primary major lower extremity amputation were also excluded. A formal written consent for ethical approval was not required according to the criteria of the Central Committee on Research Involving Human Subjects. The institutional review board (AMOA) approved this study due to its observational nature. ${ }^{11}$ This study was conducted in accordance with the Declaration of Helsinki.

After careful consideration of standard diagnostics (eg duplex ultrasound, computed tomographic angiography, and/or magnetic resonance angiography) in the outpatient clinic and The Transatlantic Inter-Society Consensus (TASC II) classification, a panel of experts recommended each patient a particular treatment in a weekly multidisciplinary vascular conference. ${ }^{11}$ The recommendation of treatment was based on current clinical practice in addition to the patient's condition. As reported previously, ${ }^{11}$ the treatment options were endovascular revascularization, surgical revascularization, or conservative therapy (local wound care, antibiotics, and analgesics with or without minor amputation).

At patient inclusion, sociodemographic and several clinical characteristics were obtained from each patient. Sociodemographic characteristics included age, sex, marital status, educational level and level of independence (eg independent, home with help, nursing home or care facility). Clinical characteristics were Rutherford classification, current smoking, and chronic comorbidities (renal impairment, diabetes mellitus, cardiac disease). During a period of 24 months, follow-up measurements were performed at five to seven days, six weeks, six months, 12 months, and 24 months after the initial therapy. At baseline and at each follow-up moment, patients completed the WHOQOLBREF questionnaire to determine QoL and the 12-Item Short Form Health Survey (SF-12) to measure HS. ${ }^{16,17}$ HS questionnaires evaluate perceived physical, psychological, and social functioning. They assess patients' daily activities and only provide an objective assessment of functioning, provided by the patients' themselves. ${ }^{18-21} \mathrm{QoL}$ questionnaires are a subjective appraisal of physical, psychological, and social functioning. Hence, QoL concerns patients' satisfaction with functioning. ${ }^{22}$ The treatment course (eg treatment, complications of treatment, time in hospital, time of amputation, time of death, etc) was also duly noted during follow-up. 


\section{Statistical Analysis}

Latent class trajectory analysis is a statistical method for identifying unobservable (eg latent) subgroups within a population based on the population's pattern of answers on categorical and continuous observed variables. With latent class trajectory analysis, a prediction model why patients fall into certain subgroups can be created. Latent class trajectory analysis was used to classify patients into distinctive subgroups, each showing a unique QoL or HS trajectory over the two-year follow-up. ${ }^{23}$ Latent class trajectory analyses were performed separately for the following outcomes: overall QoL, physical QoL, physiological QoL, physical HS, and psychological HS. For each outcome, models varying from one to eight distinctive trajectory classes (eg similar scoring pattern on the measured variable) were estimated. The relative fit measures Akaike's Information Criterion (AIC), Bayesian Information Criterion (BIC), and AIC3 were used to define the optimal number of classes. ${ }^{24}$ If there was any inconsistency in the conclusions provided by these fit measures, we chose the number of classes that showed the best fit according to $\mathrm{AIC} 3$, as this fit measure was shown to perform best in selecting the optimal number of classes. $^{25}$ After the best fitting model was selected, the associations between latent trajectory class membership and the clinical and sociodemographic covariates could be determined using a multinomial logistic regression analysis. Missing values in the outcome variables were directly handled in the latent class model through full information maximum likelihood estimation. Latent gold 5.0 was used both to fit the latent class models and to predict class membership based on the multinomial logistic regression. ${ }^{26}$

The computerized software package IBM SPSS 23.0 performed all other statistical analyses. Shapiro-Wilk test was used to assess normality of continuous data. Gaussianshaped distributions were expressed as mean and standard deviation. Non-normally distributed continuous data were expressed as median and interquartile range. The change of QoL within treatment group was analyzed by linear mixed modelling. Within mixed modeling, custom hypothesis tests were used to assess differences between the follow-up measurements. One-sample t tests were used to compare the mean QoL and HS estimates to corresponding estimates in the general elderly population. A $p$-value below 0.05 (two-sided) indicated a statistically significant result.

\section{Results}

Between January 2012 and February 2016, 195 patients were included in this study and 192 patients were excluded from this study. There were 187 exclusions due to cognitive impairment or refusal to participate; five patients were excluded based on primary amputation. ${ }^{11}$ Included patients were divided into three treatment groups. ${ }^{11}$ Patients were treated with endovascular revascularization $(n=82)$, surgical revascularization $(n=67)$, or they received conservative therapy $(n=46)$.

\section{Patient Characteristics}

The baseline characteristics are presented in Table 1. Of the 195 patients, 56\% were male and 33\% had a Rutherford

Table I Baseline Characteristics

\begin{tabular}{|l|l|}
\hline & Total n= I95 (100) \\
\hline $\begin{array}{l}\text { Gender } \\
\text { Male }\end{array}$ & $110(56)$ \\
Female & $85(44)$ \\
\hline Age & \\
Median age (IQR) & $80(75,84)$ \\
\hline Rutherford class & \\
Category 4 & $64(33)$ \\
Category 5/6 & $131(67)$ \\
\hline Comorbidity & \\
Pulmonary & $108(55)$ \\
Cardiac & $134(69)$ \\
Neurological & $63(32)$ \\
Arthritis & $58(30)$ \\
\hline Vascular risk factors & \\
Hypertension & $130(57)$ \\
Diabetes mellitus & $94(48)$ \\
Renal impairment & $111(57)$ \\
Currently smoking & $45(23)$ \\
\hline Preoperative risk scores & $67(34)$ \\
ASA score 2 & $56(24)$ \\
ASA score 3 & $124(64)$ \\
Endovascular revascularization 4 & $18(9)$ \\
\hline V-POssum score & $55(35,73)$ \\
Median morbidity (IQR) & $15,25)$ \\
\hline Primary Treatment & \\
\hline
\end{tabular}

Note: Data are presented as number of patients and (\%), unless otherwise specified. 
classification of 4 . The median age was 80 years old. Patients selected for surgical treatment were significantly younger ( $p=0.001)$ and had less comorbidity compared to patients selected for endovascular revascularization and conservative therapy. Patients who received conservative therapy had significantly higher preoperative risk scores (ASA-score). ${ }^{11}$ The baseline characteristics for the treatment groups separately of this study were previously published by Steunenberg et al. ${ }^{11}$ The flow chart (Figure 1) provides an overview of the clinical course of the patients included in our study. The overall two-year mortality was 42.1\%. At the two-year follow-up measurement point, 97 patients were eligible for outcome determination. For 31 patients out of the initial cohort of 195 patients, there was no follow-up data available for QoL and HS questionnaires because of loss to follow-up (mostly due to inability to complete the questionnaires). Yet, the medical follow-up data was available for all patients.

\section{Long-term Outcome Quality of Life}

Figure 2 presents the QoL of patients after one and two years of follow-up. The one-year results were previously published by Steunenberg et al. ${ }^{27}$ The overall QoL scores were significantly improved at the two-year follow-up measurement when compared to the baseline measurement in the surgically treated group and in the group receiving conservative treatment (respectively, 3.7 vs 3.0, 95\%CI: $0.34-0.83, p<0.001$ and. 3.3 vs $3.1,95 \% \mathrm{CI}: 0.00-0.78, p=0.049)$.

After two years, physical QoL had a significantly higher score than the baseline measurement in all treatment groups: endovascular treatment (13.7 vs 10.9 , 95\% CI: $1.74-3.63$,

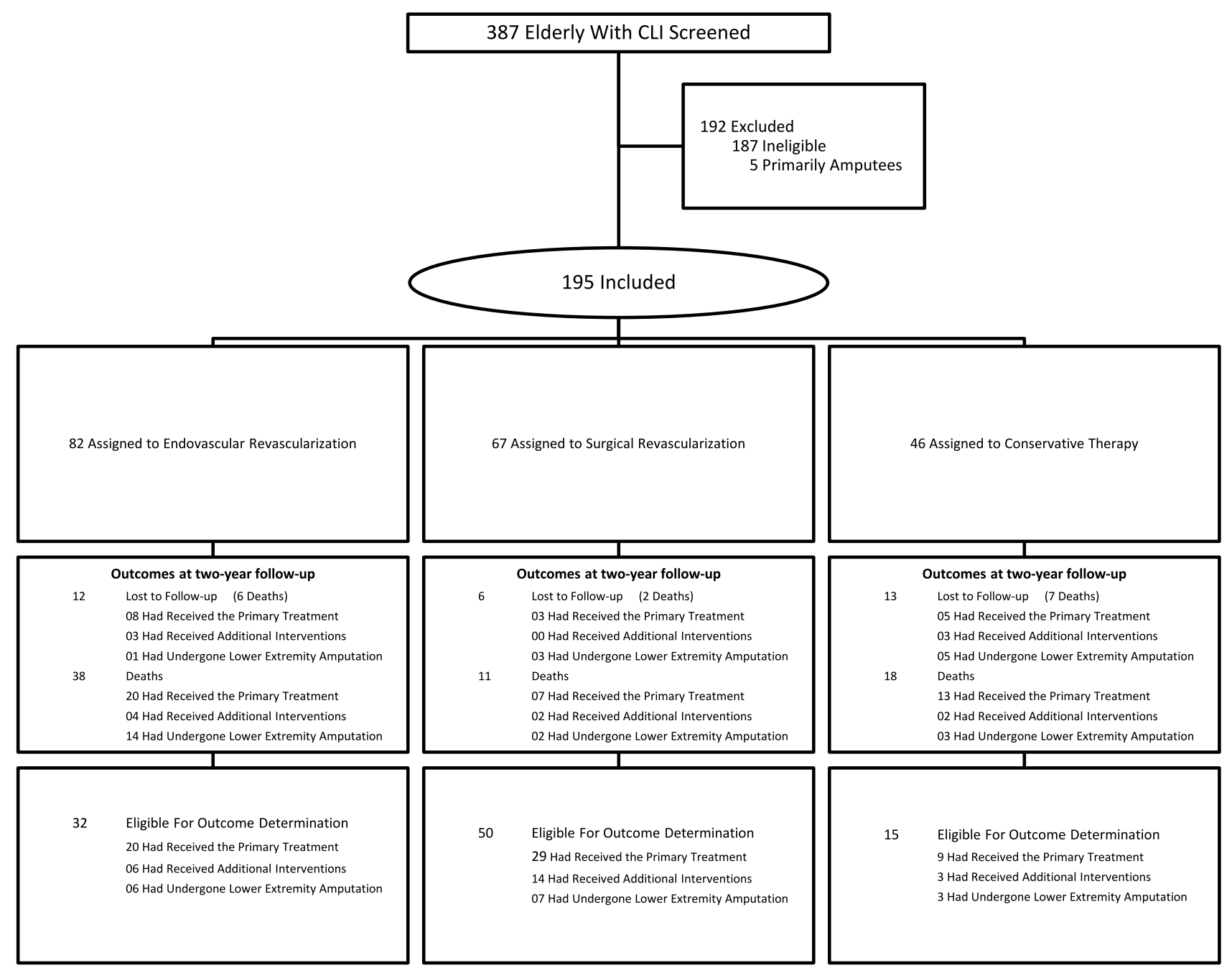

Figure I Screened and Included Patients. 


\section{Endovascular treatment}

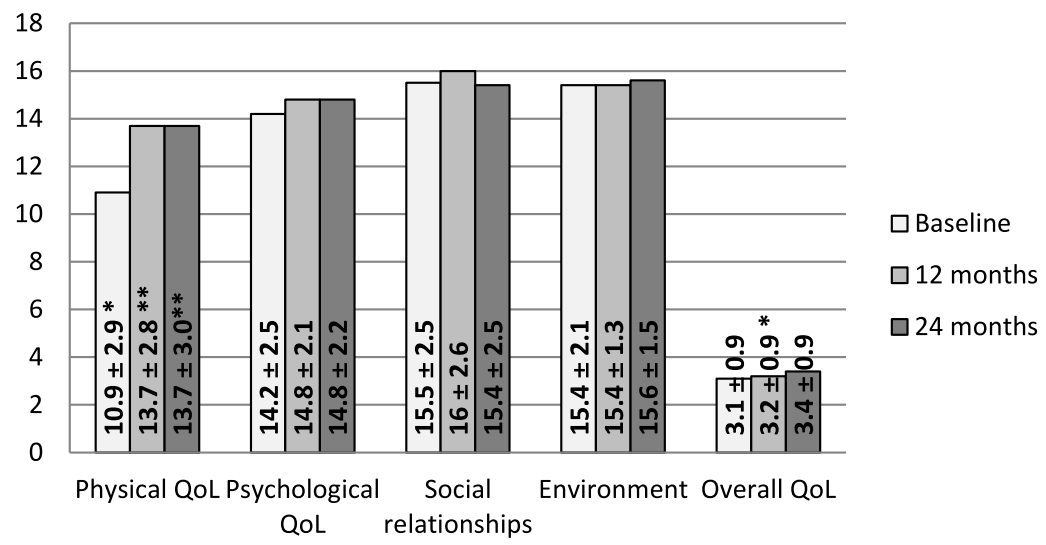

\section{Surgical treatment}

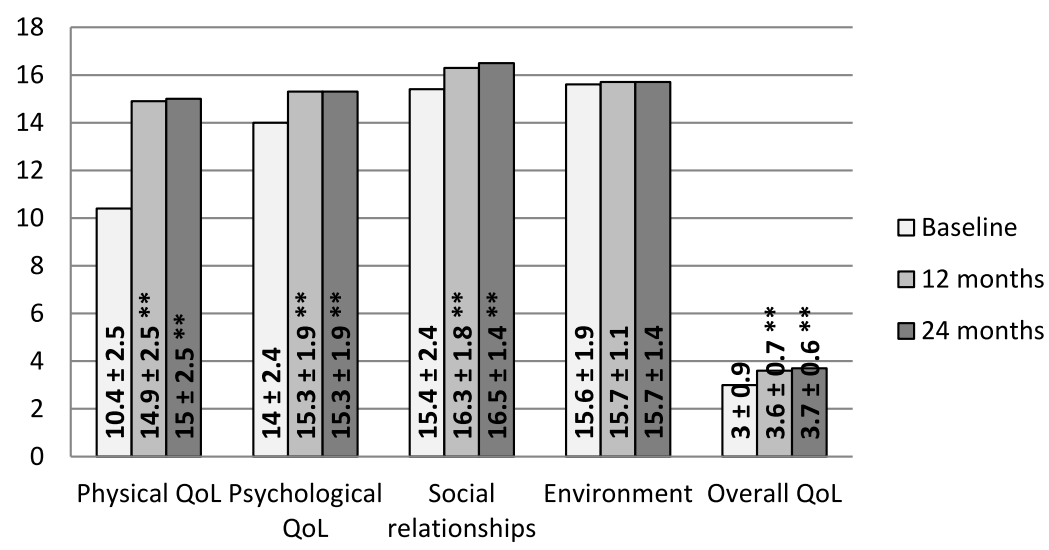

\section{Conservative treatment}

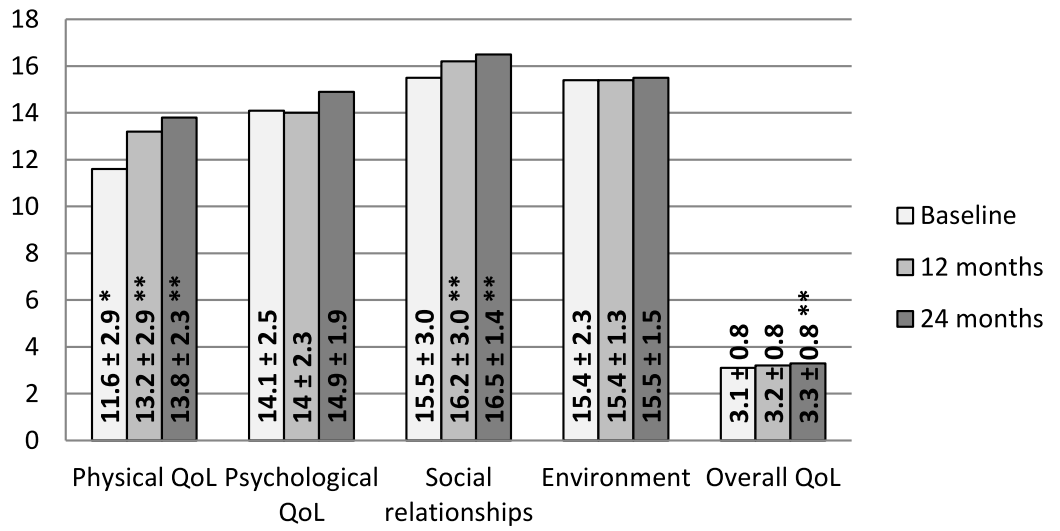

Figure 2 Quality of Life. Data is presented as mean and standard deviation. *Significant difference between the treatment group and the surgical treatment group ( $p<0.05$ ). **Significant difference in the treatment group between this measurement and baseline $(p<0.05)$.

$p<0.001)$, surgical treatment (15.0 vs $10.4,95 \%$ CI: $3.64-$ $5.28, p<0.001)$, and conservative treatment $(13.8$ vs 11.6 , 95\%CI: $1.14-3.88, p<0.001)$. However, the psychological QoL only showed significant improvement in the surgically treated group at two-year follow-up (15.3 vs $14.0,95 \% \mathrm{CI}$ :
$0.68-1.89, p<0.001)$. Moreover, there were also no statistically significant differences between the treatment groups for all QoL measurements at two-year follow-up.

In Table 2, the mean QoL scores at baseline and two-year follow-up are compared to the mean estimated normal scores 
Table 2 WHOQOL-BREF Compared to Normal Values for Elderly

\begin{tabular}{|c|c|c|c|c|c|c|}
\hline & $\mathbf{n}$ & $\begin{array}{l}\text { Mean } \\
\text { Estimate }\end{array}$ & $\begin{array}{l}\text { Mean Estimate in the } \\
\text { General Elderly } \\
\text { Population }\end{array}$ & $\begin{array}{l}\text { Mean } \\
\text { Difference }\end{array}$ & $95 \% \mathrm{Cl}$ & $p$-value \\
\hline \multicolumn{7}{|c|}{ Baseline QoL domains } \\
\hline Overall & & & 3.90 & & & \\
\hline Total cohort & 193 & 3.086 & & -0.815 & $-0.936 ;-0.693$ & $<0.001$ \\
\hline Endovascular group & 81 & 3.105 & & -0.795 & $-0.992 ;-0.598$ & $<0.001$ \\
\hline Surgery group & 67 & 3.045 & & -0.855 & $-1.067 ;-0.643$ & $<0.001$ \\
\hline Conservative group & 45 & 3.111 & & -0.789 & $-1.024 ;-0.554$ & $<0.001$ \\
\hline Physical & & & 14.869 & & & \\
\hline Total cohort & 192 & 10.903 & & -3.966 & $-4.362 ;-3.570$ & $<0.001$ \\
\hline Endovascular group & 81 & 10.899 & & -3.970 & $-4.604 ;-3.337$ & $<0.001$ \\
\hline Surgery group & 65 & 10.422 & & -4.447 & $-5.074 ;-3.819$ & $<0.001$ \\
\hline Conservative group & 46 & 11.589 & & -3.280 & $-4.137 ;-2.422$ & $<0.001$ \\
\hline Psychological & & & $|4.87|$ & & & \\
\hline Total cohort & 195 & 14.088 & & -0.783 & $-1.129 ;-0.437$ & $<0.001$ \\
\hline Endovascular group & 82 & 14.175 & & -0.696 & $-1.239 ;-0.154$ & 0.012 \\
\hline Surgery group & 67 & 13.967 & & -0.904 & $-1.498 ;-0.310$ & 0.003 \\
\hline Conservative group & 46 & 14.109 & & -0.762 & $-1.50 \mathrm{I} ;-0.023$ & 0.43 \\
\hline Social relationship & & & $|5.25|$ & & & \\
\hline Total cohort & 191 & 15.467 & & 0.218 & $-0.1498 ; 0.586$ & 0.244 \\
\hline Endovascular group & 80 & 15.500 & & 0.249 & $-0.312 ; 0.810$ & 0.380 \\
\hline Surgery group & 65 & 15.426 & & 0.174 & $-0.416 ; 0.764$ & 0.557 \\
\hline Conservative group & 46 & 15.478 & & 0.227 & $-0.656 ; 1.109$ & 0.006 \\
\hline Environment & & & 15.573 & & & \\
\hline Total cohort & 188 & 15.479 & & -0.093 & $-0.386 ; 0.200$ & 0.531 \\
\hline Endovascular group & 79 & 15.443 & & -0.130 & $-0.590 ; 0.331$ & 0.577 \\
\hline Surgery group & 63 & 15.564 & & -0.009 & $-0.478 ; 0.459$ & 0.969 \\
\hline Conservative group & 46 & 15.427 & & -0.146 & $-0.816 ; 0.524$ & 0.664 \\
\hline \multicolumn{7}{|c|}{$\begin{array}{l}\text { QoL domains at two-year } \\
\text { follow-up }\end{array}$} \\
\hline Overall & & & 3.90 & & & \\
\hline Total cohort & 87 & 3.512 & & -0.388 & $-0.545 ;-0.231$ & $<0.001$ \\
\hline Endovascular group & 28 & 3.375 & & -0.525 & $-0.865 ;-0.185$ & 0.004 \\
\hline Surgery group & 43 & 3.651 & & -0.249 & $-0.422 ;-0.076$ & 0.006 \\
\hline Conservative group & 13 & 3.346 & & -0.554 & $-1.038 ;-0.070$ & 0.028 \\
\hline Physical & & & 14.869 & & & \\
\hline Total cohort & 84 & 14.364 & & -0.505 & $1.094 ; 0.084$ & 0.092 \\
\hline Endovascular group & 28 & 13.704 & & -1.165 & $-2.34 I ; 0.011$ & 0.052 \\
\hline Surgery group & 43 & 14.950 & & 0.081 & $-0.698 ; 0.860$ & 0.834 \\
\hline Conservative group & 13 & 13.846 & & -1.023 & $-2.419 ; 0.374$ & 0.137 \\
\hline Psychological & & & $|4.87|$ & & & \\
\hline Total cohort & 84 & $|5.07|$ & & 0.200 & $-0.226 ; 0.627$ & 0.353 \\
\hline Endovascular group & 28 & 14.810 & & -0.062 & $-0.904 ; 0.78$ I & 0.882 \\
\hline Surgery group & 43 & 15.302 & & 0.431 & $-0.144 ; 1.006$ & 0.138 \\
\hline Conservative group & 13 & 14.872 & & 0.001 & $-1.131 ; 1.133$ & 0.999 \\
\hline Social relationship & & & $|5.25|$ & & & \\
\hline Total cohort & 83 & 16.137 & & 0.885 & $0.466 ; 1.305$ & $<0.001$ \\
\hline Endovascular group & 28 & 15.405 & & 0.153 & $-0.830 ; 1.137$ & 0.751 \\
\hline Surgery group & 42 & 16.508 & & 1.277 & $0.810 ; 1.703$ & $<0.001$ \\
\hline
\end{tabular}

(Continued) 
Table 2 (Continued).

\begin{tabular}{|c|c|c|c|c|c|c|}
\hline & $\mathbf{n}$ & $\begin{array}{l}\text { Mean } \\
\text { Estimate }\end{array}$ & $\begin{array}{l}\text { Mean Estimate in the } \\
\text { General Elderly } \\
\text { Population }\end{array}$ & $\begin{array}{l}\text { Mean } \\
\text { Difference }\end{array}$ & $95 \% \mathrm{Cl}$ & $p$-value \\
\hline Conservative group & 13 & 16.513 & & 1.261 & $0.437 ; 2.086$ & 0.006 \\
\hline Environment & & & 15.573 & & & \\
\hline Total cohort & 84 & 15.643 & & 0.070 & $-0.240 ; 0.380$ & 0.653 \\
\hline Endovascular group & 28 & $|5.57|$ & & -0.001 & $-0.576 ; 0.574$ & 0.997 \\
\hline Surgery group & 43 & $|5.72|$ & & 0.148 & $-0.286 ; 0.583$ & 0.494 \\
\hline Conservative group & 13 & 15.539 & & -0.034 & $-0.919 ; 0.851$ & 0.934 \\
\hline
\end{tabular}

Notes: Data presented as mean; a $p$-value of $<0.05$ represents a significant difference between the mean value of the general elderly population and the value in this cohort (indicated with bold front). The value of the general elderly population is based on reference 28 .

in the elderly population. ${ }^{28}$ At baseline, physical QoL and psychological QoL were significantly lower than the normal values of elderly. There was no significant difference between physical QoL, psychological QoL or environmental two-year results and the corresponding normal values for elderly for all treatment groups. The overall QoL score was significantly lower in comparison with normal value for elderly at baseline and at two-year follow-up. The two-year social relationships score was significantly higher in comparison with normal value for elderly.

\section{Health Status}

HS after one-year and two-year follow-up is presented in Figure 3. After two years, physical HS (SF-12) significantly improved compared to the one-year follow-up measurement (37.3 vs 28.0 , 95\% CI: $2.75-7.25, p<0.001$ ) and to the baseline measurement $(42.5$ vs $28.0,95 \% \mathrm{CI}$ : $10.48-16.58$, $p<0.001)$ in the surgical revascularization group. The physical HS (SF-12) significantly improved compared to the baseline measurement in the endovascular group (37.4 vs 28.9, 95\%CI: 2.53-9.46, $p=0.001)$. For all treatment groups, the mental HS scores were significantly better than the baseline measurement. The mental HS scores were also improved in comparison with the one-year follow-up measurement: endovascular treatment $(46.8$ vs $42.5,95 \% \mathrm{CI}: 1.90-7.63$, $p=0.001)$, surgical treatment $(51.5$ vs $43.9,95 \% \mathrm{CI}$ : 4.53 9.38, $p<0.001$ ), and conservative treatment (45.8 vs 39.5 , 95\%CI: $1.05-9.62, p=0.009$ ).

The scores of the physical and mental domains of the SF-12 questionnaire were compared to the mean estimated normal scores in the elderly population (Table 3). ${ }^{29}$ At baseline, both domains of the SF-12 were significantly impaired in the elderly CLTI population of this study. After two years, only surgically treated patients had physical HS scores corresponding with the scores of their peers.

\section{Trajectories}

The number of latent trajectory classes was found to be four for the QoL domains and five for the HS domains based on the lowest AIC3-value (Supplement Table A). Trajectories of the QoL domains are presented in Figure 4 and trajectories of the HS domains are presented in Figure 5. In

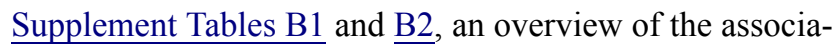
tions between the latent trajectory classes and the sociodemographic and clinical characteristics is provided for the overall, physical and psychological domains of QoL and the physical and mental domains of HS. Because of the large number of tested associations, a Bonferroni correction was applied resulting in an adjusted significance level of 0.05/14 predictors $=0.0035$. Overall, there were no overlapping risk factors for poorer QoL and/or HS in this patient population.

\section{Discussion}

Although QoL and HS are discussed for CLTI patients in current literature, ${ }^{11-13,30-32}$ there is a paucity of information about long-term QoL and HS outcomes in elderly CLTI patients. In our study, there is a persistent gain in QoL and HS for the surgically treated patients after two years. For all treatment groups, the physical QoL is significantly better compared to the baseline measurement in the long-term. Concerning physical HS, both surgically and endovascular treated patients improve significantly on this domain of the SF-12. Interestingly, conservatively treated patients do not show any improvements on their physical HS scores during two years of follow-up. More importantly, physical QoL did not differ from the corresponding normal values for patients in all treatment groups after two-years of follow-up. ${ }^{28}$ But then again, the overall QoL score was significantly lower in comparison with normal value for elderly after two years of follow-up. 


\section{Endovascular treatment}

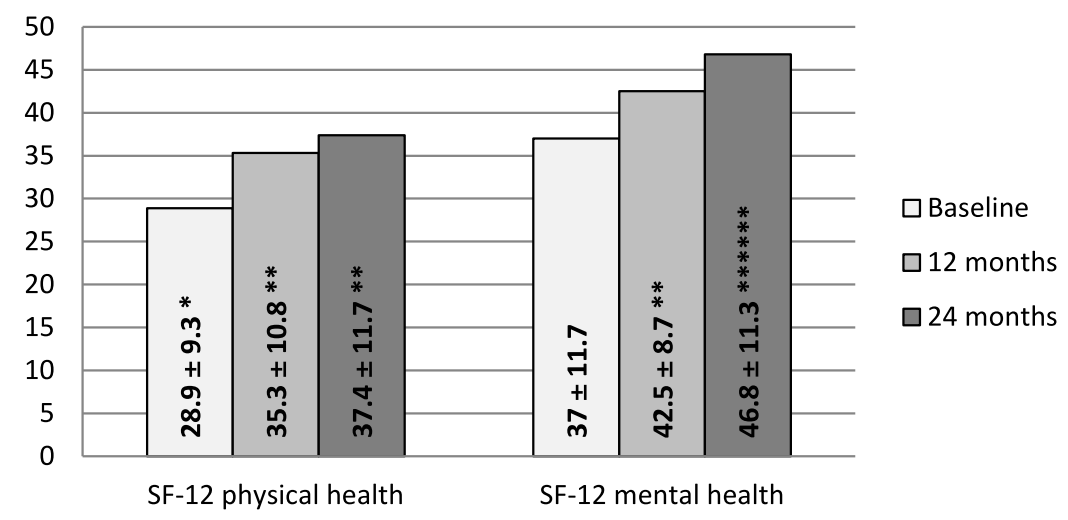

Surgical treatment

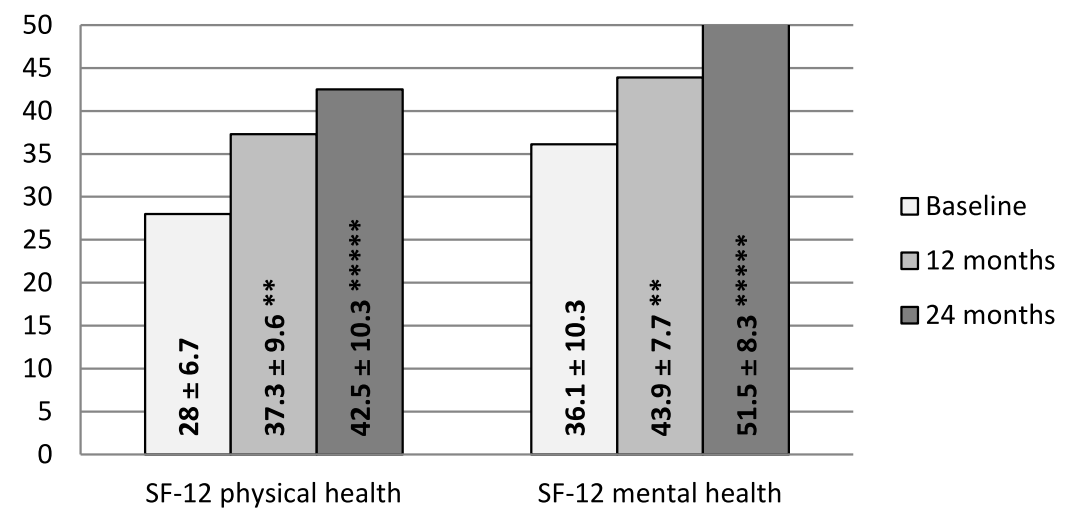

Conservative treatment

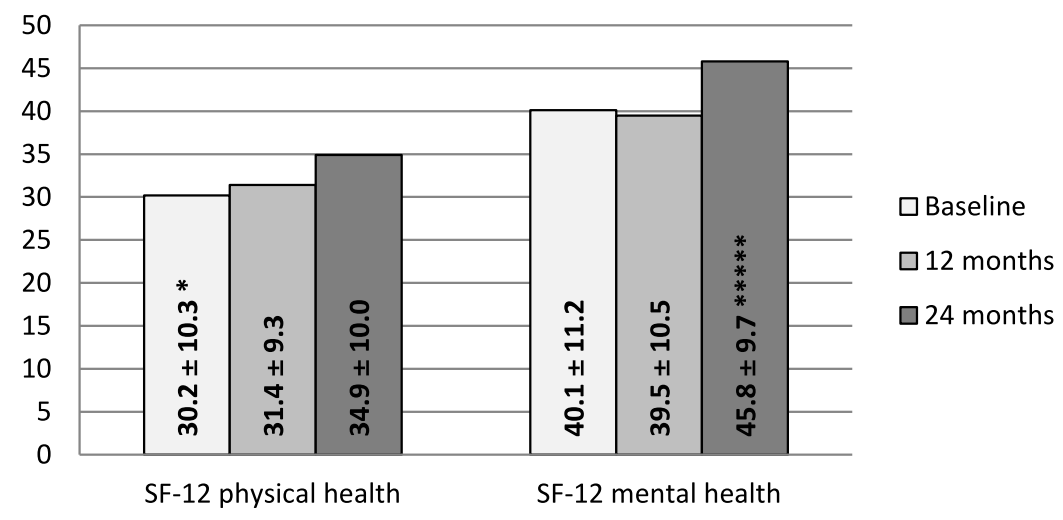

Figure 3 Health status (SF-12). Data is presented as mean and standard deviation. *Significant difference between the treatment group and the surgical treatment group $(p<0.05)$. **Significant difference in the treatment group between this measurement and baseline $(p<0.05)$. $* * *$ Significant difference in the treatment group between this measurement and the 12-month measurement $(p<0.05)$.

Our results are only partly in line with previous studies conducted with CLTI patients. The BASIL trial stated that both endovascular and surgical revascularization led to an improved long-term QoL. ${ }^{12}$ In our study, the surgically treated rose in QoL scores and endovascular treated patients only gained in physical QoL. A possible explanation for this might be that patients were included in our study despite comorbidities or type of anatomic lesion. Due to the latter, patients could only be randomized in the BASIL trial if patients were suited for open or 
Table 3 HS Compared to Normal Values for Elderly

\begin{tabular}{|c|c|c|c|c|c|c|}
\hline & $\mathbf{n}$ & Value & $\begin{array}{l}\text { Value of General } \\
\text { Elderly Population }\end{array}$ & Mean Difference & $P$-value & $95 \% \mathrm{Cl}$ \\
\hline \multicolumn{7}{|l|}{ Baseline HS domains } \\
\hline Physical & & & 44.22 & & & \\
\hline Total cohort & 190 & 28.87 & & -15.35 & $<0.001$ & $-16.596 ;-14.097$ \\
\hline Endovascular group & 78 & 28.88 & & -15.34 & $<0.001$ & $-17.427 ; 13.256$ \\
\hline Surgery group & 66 & 27.98 & & -16.24 & $<0.001$ & $-17.880 ;-14.608$ \\
\hline Conservative group & 46 & 30.15 & & -14.07 & $<0.001$ & $-17.140 ;-10.999$ \\
\hline Mental & & & 47.71 & & & \\
\hline Total cohort & 190 & 37.44 & & -4.58 & $<0.001$ & II. $.863 ;-8.670$ \\
\hline Endovascular group & 78 & 36.98 & & -10.73 & $<0.001$ & $-13.376 ;-8.090$ \\
\hline Surgery group & 66 & 36.13 & & -11.57 & $<0.001$ & $-14.103 ;-9.054$ \\
\hline Conservative group & 46 & 40.12 & & -7.59 & $<0.001$ & $-10.9 \mid 4 ;-4.272$ \\
\hline \multicolumn{7}{|c|}{$\begin{array}{l}\text { HS domains at two-year } \\
\text { follow-up }\end{array}$} \\
\hline Physical & & & 44.22 & & & \\
\hline Total cohort & 84 & 39.64 & & -10.27 & $<0.001$ & $-6.984 ; 2.186$ \\
\hline Endovascular group & 28 & 37.39 & & -6.83 & 0.005 & $-11.381 ;-2.275$ \\
\hline Surgery group & 43 & 42.53 & & -1.69 & 0.287 & $-4.854 ; 1.474$ \\
\hline Conservative group & 13 & 34.89 & & -9.33 & 0.005 & $-15.345 ;-3.312$ \\
\hline Mental & & & 47.71 & & & \\
\hline Total cohort & 84 & 49.07 & & 1.36 & 0.209 & $-0.774 ; 3.490$ \\
\hline Endovascular group & 28 & 46.78 & & -0.93 & 0.667 & $-5.320 ; 3.457$ \\
\hline Surgery group & 43 & 51.54 & & 3.83 & 0.004 & $1.289 ; 6.376$ \\
\hline Conservative group & 13 & 45.81 & & -1.90 & 0.496 & $-7.778 ; 3.984$ \\
\hline
\end{tabular}

Notes: Data presented as mean; a $p$-value of $<0.05$ represents a significant difference between the mean value of the general elderly population and the value in this cohort (indicated with bold front). The value of the general elderly population is based on reference 29.

endovascular revascularization. Thus, only half of the elderly patients with infra-inguinal lesions could be included in the BASIL trial. Similar to our study, a significant difference in QoL between the two groups could not be detected. ${ }^{12,33}$ Still, it remains uncertain whether the BASIL trial's QoL results reflect the underlying QoL. It can be argued that the disease-specific VascuQol questionnaire does not represent QoL. The measurement of physical function in the VascuQol questionnaire represents an "objective" assessment of performing activities instead of the patient's perception of his overall functioning. ${ }^{34}$ Therefore, the VascuQol questionnaire is an objective assessment of functioning eg HS. ${ }^{4}$ In addition, the differentiating power in CLTI patients is deficient and therefore it may not be applicable to the CLTI patient group. ${ }^{35}$

Van Hattem et al indicated that HS deteriorates after peripheral bypass surgery in the long-term (mean follow-up 11 years). ${ }^{13}$ There is a lack of other studies on the long-term HS of CLTI patients. In our study, surgically and endovascular treated patients show a significant improvement of physical and mental HS after two years of follow-up.
Patients who received conservative treatment do not show any deterioration in the physical and mental HS domains during two years of follow-up. This study indicated that surviving patients do not experience worse HS two years after the start of any treatment.

An understanding of the profile of elderly CLTI patients to identify patients with factors that could impair QoL and HS was lacking. In the latent class analysis, patients with the lowest and highest QoL and HS trajectories could be identified. The findings of this prospective observational cohort study may help us recognize elderly CLTI patients that may need a careful reconsideration of the intended treatment. Consequently, a tailored approach in the management of CLTI can be facilitated when there is insight into the variables that make a patient prone to better or worse QoL or HS outcomes. With respect to shared decision making, these distinctive variables will provide a very important facet in personalized medicine.

In patients with IC, prior reports have focussed on factors that might influence the course of HS. Poorer HS 

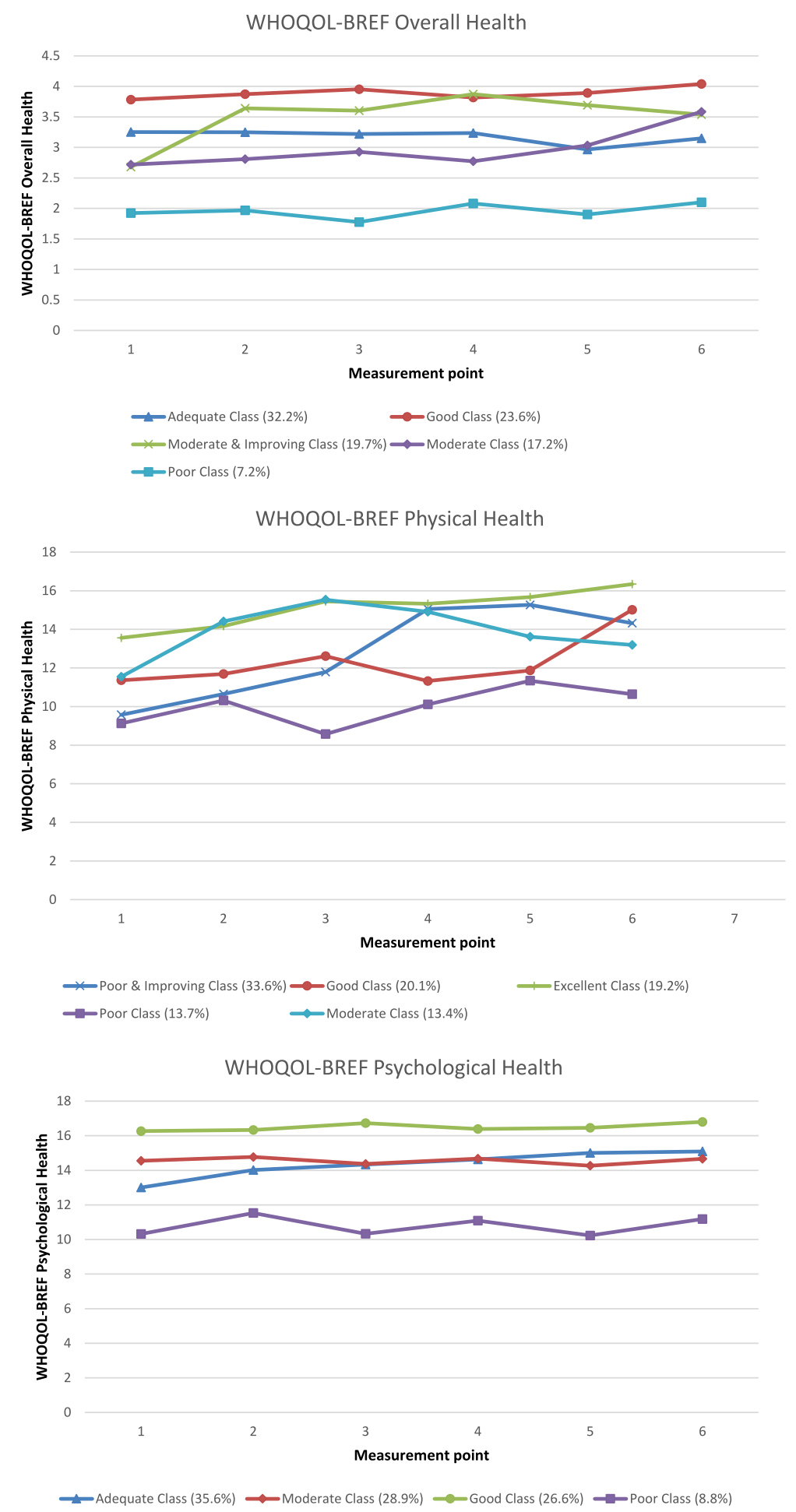

Figure 4 Quality of Life Trajectories.

in these patients was associated with younger age, female sex, the presence of cardiac disease, worsening ankle-brachial index and not having a partner. ${ }^{15,36-38}$ However, these results do not apply to the elderly CLTI patients in this study. No sociodemographic or clinical variables significantly influenced the lowest QoL and HS trajectories.

Our study has limitations. Firstly, in this observational study, patients were not randomized to treatment. Thereby, this study suffers from selection bias. Nevertheless, a selection 


\section{SF-12 Physical Health}

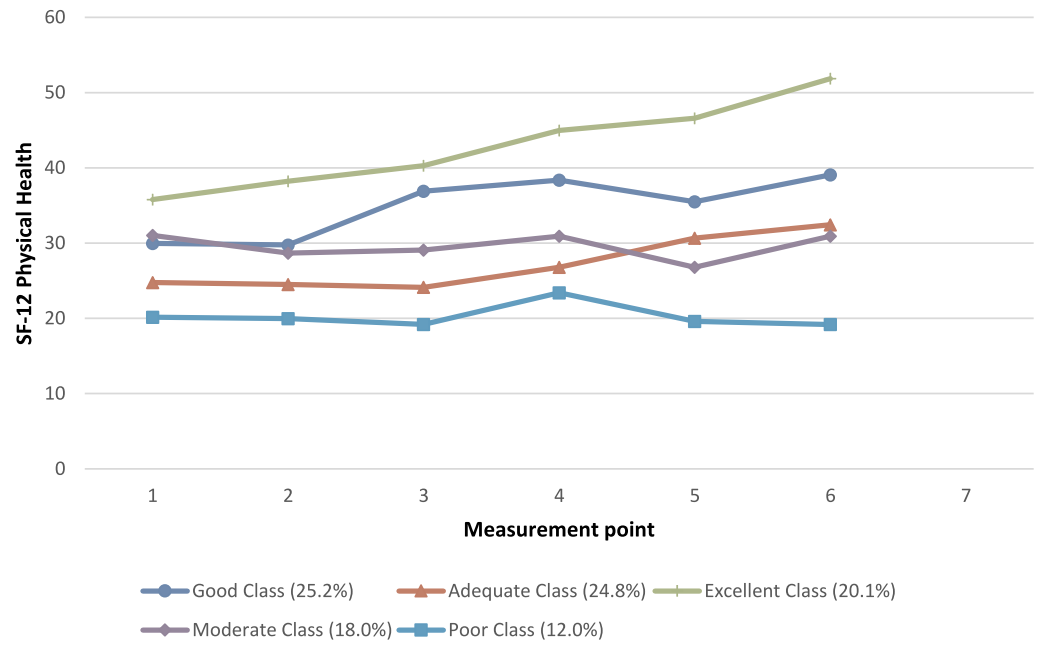

SF-12 Psychological Health

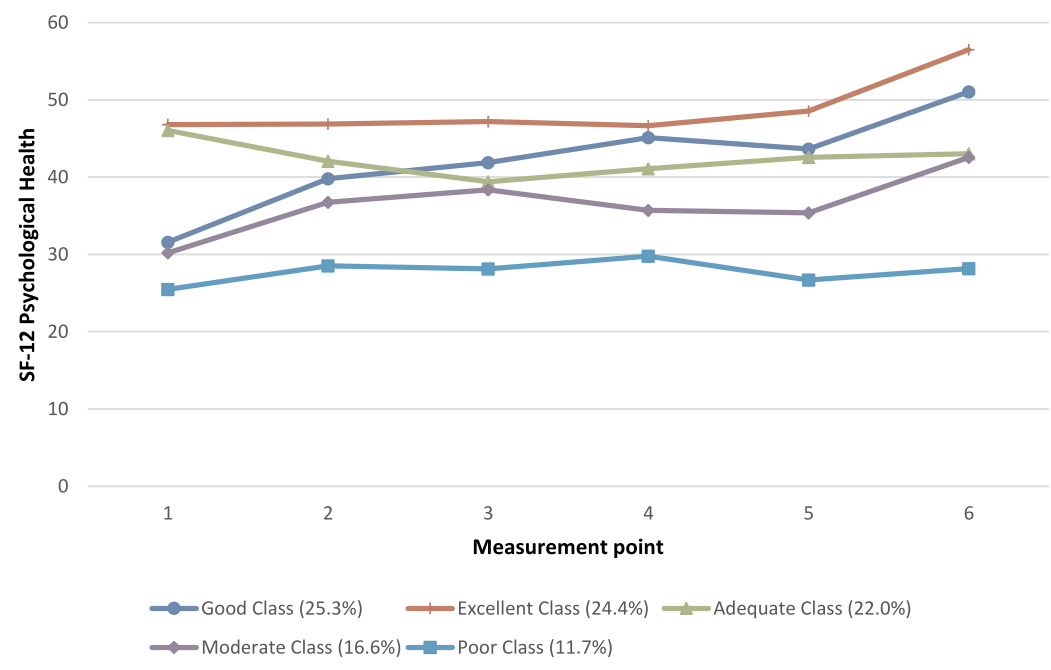

Figure 5 Health Status Trajectories.

bias even exists when CLTI patients are randomized to treatment. Not all patients are suitable for both surgical and endovascular revascularization. Moreover, some patients cannot undergo either of these treatments. So in this study, the treatment selection after counselling in a multidisciplinary vascular conference resembles current clinical practice. Secondly, in this study questionnaires were conducted. In survey research a non-response bias is always present. The main reason for loss to follow-up was incapability of completing questionnaires during follow-up. Still, response rates were high when compared to the BASIL trial and PREVENT trial. At two years follow-up $84.1 \%$ patients alive completed the questionnaires. In the BASIL trial, the response rate was $70 \% .{ }^{12}$ Response rate was similar in the PREVENT trial; 62.5\% at one-year follow- up. ${ }^{39}$ Thirdly, patients with primary amputations were excluded due to the low number of patients $(\mathrm{n}=5)$. Therefore, this study was underpowered to examine the clinical outcome of patients with a primary amputation. Future research will examine QoL and HS of primarily amputated CLTI patients. In addition, due to of the small number of surviving patients, this study did not differentiate between patients with ischemic rest pain and patients with ischemic ulcers or wounds. Previously published data of this study shows that patients with ischemic ulcers or wounds were significantly less treated with conservative treatment compared to revascularization. ${ }^{11}$ In future research, a differentiation should be made between patients with ischemic rest pain and patients with ischemic ulcers or wounds. 
Currently, long-term outcome in elderly CLTI patients are lacking. ${ }^{40}$ This study shows that physical and psychological QoL levels in surviving elderly CLTI patients do not differ from the corresponding normal values of elderly people. Moreover, physical QoL increases after revascularization and conservative treatment after two years of follow-up. Physical HS only improves in revascularized patients. This was also the first study to evaluate the trajectory of elderly CLTI patients' QoL or HS after treatment. Interestingly, no sociodemographic or clinical variables significantly influenced the lowest QoL and HS trajectories. It is hoped that this study encourages further analysis of the influence of biopsychosocial characteristics on QoL and HS in elderly CLTI patients in order to achieve personalized medicine and aid the shared decision making process.

\section{Acknowledgments}

N. Verbogt, Department of Surgery, Amphia Hospital, Breda, The Netherlands for data collection

\section{Disclosure}

The authors report no conflicts of interest in this work.

\section{References}

1. Farber A, Eberhardt RT. The current state of critical limb ischemia a systematic review. JAMA Surg. 2016;151(11):1070-1077. doi:10.1001/jamasurg.2016.2018

2. Becker F, Robert-Ebadi H, Ricco J-B, et al. Chapter I: definitions, epidemiology, clinical presentation and prognosis. Eur J Vasc Endovasc Surg. 2011;42(S3):S4-12. doi:10.1016/S1078-5884(11) 60009-9

3. Conte MS, Bradbury AW, Kolh P, et al. Global vascular guidelines on the management of chronic limb-threatening ischemia. Eur J Vasc Endovasc Surg. 2019;58(1):S1-S109.e33. doi:10.1016/j.ejvs.2019.05.006

4. Breek JC, De Vries J, Van Heck GL, Van Berge Henegouwen DP, Hamming JF. Assessment of disease impact in patients with intermittent claudication: discrepancy between health status and quality of life. J Vasc Surg. 2005;41(3):443-450. doi:10.1016/j.jvs.2004.12.042

5. Dua A, Lee CJ. Epidemiology of peripheral arterial disease and critical limb ischemia. Tech Vasc Interv Radiol. 2016;19(2):91-95. doi:10.1053/j.tvir.2016.04.001

6. Reinecke H, Unrath M, Freisinger E, et al. Peripheral arterial disease and critical limb ischaemia: still poor outcomes and lack of guideline adherence. Eur Heart J. 2015;36:932-938. doi:10.1093/eurheartj/ehv006

7. Teraa M, Conte MS, Moll FL, Verhaar MC. Critical limb ischemia: current trends and future directions. $J$ Am Heart Assoc. 2016;5(2):1-9. doi:10.1161/JAHA.115.002938

8. Norgren L, Hiatt WR, Dormandy JA, Nehler MR, Harris KA, Fowkes FGR. Inter-society consensus for the management of peripheral arterial disease (TASC II). J Vasc Surg. 2007;45(1):5-67. doi:10.1016/j. jvs.2006.12.037

9. de Leur K, van Zeeland MLP, Ho GH, De Groot HGW, Veen EJ, van der Laan L. Treatment for critical lower limb ischemia in elderly patients. World J Surg. 2012;36(12):2937-2943. doi:10.1007/s00268012-1758-y
10. Thomas AR, Raats JW, Lensvelt MMA, de Groot HGW, Veen EJ, van der Laan L. Conservative treatment in selected patients with severe critical limb ischemia. World J Surg. 2015;39:2090-2095. doi:10.1007/s00268-015-3069-6

11. Steunenberg S, de Vries J, Raats JW, et al. Quality of life and mortality after endovascular, surgical or conservative treatment of elderly suffering from critical limb ischemia. Ann Vasc Surg. 2018;51:95-105. doi:10.1016/j.avsg.2018.02.044

12. Forbes JF, Adam DJ, Bell J, et al. Bypass versus Angioplasty in Severe Ischaemia of the Leg (BASIL) trial: health-related quality of life outcomes, resource utilization, and cost- effectiveness analysis. $J$ Vasc Surg. 2010;51(10S):43S-51S. doi:10.1016/j.jvs.2010.01.076

13. van Hattum ES, Tangelder MJD, Lawson JA, Moll FL, Algra A. The quality of life in patients after peripheral bypass surgery deteriorates at long-term follow-up. $J$ Vasc Surg. 2009;53(3):643-650. doi:10.1016/j.jvs.2010.09.021

14. Donker JMW, De VJ, Ho GH, et al. Review: quality of life in lower limb peripheral vascular surgery. Vascular. 2016;24(1):88-95. doi:10.1177/1708538115578961

15. Noyes AM, Abbott JD, Gosch K, et al. Association between health status and sociodemographic, clinical and treatment disparities in the Patient-centered Outcomes Related to TReatment Practices in Peripheral Arterial Disease: investigating Trajectories (PORTRAIT) registry. Vasc Med. 2018;23(1):32-38.

16. Nelson CB, Lotfy M, O'Connell KA, Group W. The World Health Organization's WHOQOL-BREF quality of life assessment: psychometric properties and results of the international field trial. A report from the WHOQOL group. Qual Life Res. 2004;13(2):199-310.

17. Ware JEJ, Kosinski M, Keller SD. A 12-item short-form health survey: construction of scales and preliminary tests of reliability and validity. Med Care. 2005;14(1):151-160.

18. Vogel TR, Petroski GF, Kruse RL. Functional status of elderly adults before and after interventions for critical limb ischemia. J Vasc Surg. 2014;59(2):350-358. doi:10.1016/j.jvs.2013.08.087

19. Cieri E, Lenti M, De Rango P, Isernia G, Marucchini A, Cao P. Functional ability in patients with critical limb ischaemia is unaffected by successful revascularisation. Eur J Vasc Endovasc Surg. 2011;41(2):256-263. doi:10.1016/j.ejvs.2010.10.014

20. Muldoon MF, Barger SD, Flory JD, Manuck SB. What are quality of life measurements measuring? BMJ. 1998;316:542-545. doi:10.1136/ bmj.316.7130.542

21. Frans FA, Met R, Koelemay MJW, et al. Changes in functional status after treatment of critical limb ischemia. J Vasc Surg. 2013;58 (4):957-965. doi:10.1016/j.jvs.2013.04.034

22. Saxena S, Orley J. Quality of life assessment: the World Health Organization perspective. Eur Psychiatry. 1997;12(Suppl3):263s266s. doi:10.1016/S0924-9338(97)89095-5

23. Jones BL, Nagin DS, Roeder K. A SAS procedure based on mixture models for estimating developmental trajectories. Sociol Methods Res. 2001;29(3):374-393. doi:10.1177/0049124101029003005

24. Vermunt JK, Magidson J. Technical Guide for Latent GOLD 5.0: Basic, Advanced, and Syntax. Belmont, MA: Statistical Innovations Inc; 2013.

25. Andrews RL, Currim IS. A comparison of segment retention criteria for finite mixture logit models. J Mark Res. 2003;40(2):235-243. doi:10.1509/jmkr.40.2.235.19225

26. Vermunt JK, Magidson J. Latent GOLD 5.0. Upgrade Manual. Belmont, MA: Statistical Innovations Inc; 2013.

27. Steunenberg SL, de Vries J, Raats JW, et al. Quality of life and traditional outcome results at 1 year in elderly patients having critical limb ischemia and the role of conservative treatment. Vasc Endovascular Surg. 2020;54(2):126-134. doi:10.1177/ 1538574419885478

28. de Vries J Beyond health status: construction and validation of the Dutch WHO Quality of Life assessment instrument. Ph.D. Thesis. Tilburg: Tilburg University; 1996. 
29. Mols F, Pelle AJ, Kupper N. Normative data of the SF-12 health survey with validation using postmyocardial infarction patients in the Dutch population. Qual Life Res. 2009;18:403-414. doi:10.1007/ s11136-009-9455-5

30. Hernandez-Osma E, Cairols MA, Marti X, Barjau E, Riera S. Impact of treatment on the quality of life in patients with critical limb ischaemia. Eur J Vasc Endovasc Surg. 2002;23:491-494. doi:10.1053/ejvs.2002.1644

31. Landry GJ, Esmonde NO, Lewis JR, et al. Objective measurement of lower extremity function and quality of life after surgical revascularization for critical lower extremity ischemia. J Vasc Surg. 2014;60 (1):136-142. doi:10.1016/j.jvs.2014.01.067

32. Engelhardt M, Bruijnen H, Scharmer C, Wohlgemuth WA, Willy C, Wolfle KD. Prospective 2-years follow-up quality of life study after infrageniculate bypass surgery for limb salvage: lasting improvements only in non-diabetic patients. Eur J Vasc Endovasc Surg. 2008;36:63-70. doi:10.1016/j.ejvs.2008.01.026

33. Adam DJ, Beard JD, Cleveland T, et al. Bypass versus angioplasty in severe ischaemia of the leg (BASIL): multicentre, randomised controlled trial. Lancet. 2005;366(9501):1925-1934.

34. Conijn AP, Santema TB, Bipat S, Koelemay MJW, de Haan RJ. Clinimetric evaluation of the vascular quality of life questionnaire in patients with lower limb ischaemia. Eur J Vasc Endovasc Surg. 2017;53(3):412-418. doi:10.1016/j.ejvs.2016.12.015
35. Suckow BD, Goodney PP, Nolan BW, et al. Domains that determine quality of life in vascular amputees. Ann Vasc Surg. 2015;29(4):722730. doi:10.1016/j.avsg.2014.12.005

36. Smolderen KG, Pelle AJ, Kupper N, Mols F, Denollet J. Impact of peripheral arterial disease on health status: A comparison with chronic heart failure. J Vasc Surg. 2009;50(6):1391-1398. doi:10.1016/j.jvs.2009.07.109

37. Wu A, Coresh J, Selvin E, et al. Lower extremity peripheral artery disease and quality of life among older individuals in the community. $J$ Am Heart Assoc. 2017;6(1):e004519. doi:10.1161/JAHA.116. 004519

38. Roumia M, Aronow HD, Soukas P, et al. Sex differences in diseasespecific health status measures in patients with symptomatic peripheral artery disease: data from the PORTRAIT study. Vasc Med. 2017;22(2):103-109. doi:10.1177/1358863X16686408

39. Nguyen LL, Moneta GL, Conte MS, Bandyk DF, Clowes AW, Seely BL. Prospective multicenter study of quality of life before and after lower extremity vein bypass in 1404 patients with critical limb ischemia. J Vasc Surg. 2006;44(5):977-984. doi:10.1016/j.jvs.2006. 07.015

40. Klaphake S, de Leur K, Mulder PGH, et al. Mortality after major amputation in elderly patients with critical limb ischemia. Clin Interv Aging. 2017;12:1985-1992. doi:10.2147/CIA.S137570
Clinical Interventions in Aging

\section{Publish your work in this journal}

Clinical Interventions in Aging is an international, peer-reviewed journal focusing on evidence-based reports on the value or lack thereof of treatments intended to prevent or delay the onset of maladaptive correlates of aging in human beings. This journal is indexed on PubMed Central, MedLine, CAS, Scopus and the Elsevie

\section{Dovepress}

Bibliographic databases. The manuscript management system is completely online and includes a very quick and fair peer-review system, which is all easy to use. Visit http://www.dovepress.com testimonials.php to read real quotes from published authors. 